Original Article

\title{
Effect of bilateral lower limb strengthening exercise on balance and walking in hemiparetic patients after stroke: a randomized controlled trial
}

\author{
Hye Joo Jeon, PT, PhD ${ }^{1)}$, Byong Yong Hwang, PT, $\mathrm{PhD}^{2)^{*}}$ \\ 1) Department of Physical Therapy, Adult Rehabilitation Center, Bobath Memorial Hospital, \\ Republic of Korea \\ 2) Department of Physical Therapy, College of Public Health and Welfare, Yong In University: \\ 134 Yongindaehak-ro, Cheoin-gu, Yongin-si, Gyeonggi-do 449-714, Republic of Korea
}

\begin{abstract}
Purpose] To evaluate the effect of bilateral lower limb strengthening designed to improve balance and walking in stroke patients. [Subjects and Methods] Twenty hemiparetic stroke patients were divided into two groups: a unilateral therapy group (UTG) $(n=10)$ and a bilateral therapy group (BTG) $(n=10)$. The UTG completed strength training only in the paretic lower limb. The BTG completed strength training in the paretic and non-paretic lower limbs. Assessment tools included the functional reach test (FRT), the Berg balance scale (BBS), the timed up and go (TUG) test, and a 10-meter walk test (10MWT). [Results] In both groups, the lower limb strengthening exercise for balance and walking significantly improved the FRT, BBS, TUG, and 10MWT scores. Compared with UTG, the BTG attained significantly improved FRT and BBS scores. [Conclusion] Bilateral therapy using this lower limb strengthening exercise effectively promotes balance in hemiparetic stroke patients.

Key words: Bilateral therapy, Lower limb strengthening, Non-paretic side
\end{abstract}

(This article was submitted Sep. 7, 2017, and was accepted Nov. 16, 2017)

\section{INTRODUCTION}

A stroke occurs due to a rupture of blood vessels in the brain or an interruption to its blood supply ${ }^{1)}$, and frequently results in residual physical impairment in patients ${ }^{2}$. One of the most prominent characteristics of stroke is muscle weakness or the inability to generate normal muscle force ${ }^{3}$. It is also associated with decreased functional performance ${ }^{4}$. These functional performances include, but are not limited to, standing ${ }^{5}$, transfers $^{6}$, stair climbing $^{7}$, and gait ${ }^{8}$. Previous studies have reported many aspects of physiologic change after stroke. These changes include decreases in motor units, impaired motor unit recruitment, selective atrophy of type II muscle fibers, denervation potential, and decreased maximal contractions, all of which can cause muscle weakness ${ }^{9)}$. Strength assessment following stroke has been shown to predict the functional status of patients at discharge from inpatient rehabilitation, length of stay in inpatient rehabilitation ${ }^{10}$, future motor function status ${ }^{11)}$, and mortality ${ }^{12}$. These correlational studies have provided evidence for the hypothesis that such intervention programs intended to increase muscle strength could ultimately improve functional performance ${ }^{13}$. Recent studies have shown that lower limb strengthening programs for stroke patients can positively affect the ability to rise from a chair ${ }^{14)}$, climb stairs, and walk, as well as improve quality of life ${ }^{15)}$. To date, many strengthening exercise interventions have been used in attempts to prevent physical inactivity in stroke patients. Bilateral arm training with a rhythmic auditory cueing regimen, based on motor learning principles, has a proven positive effect on functional motor performance of the paretic upper extremity in hemiparetic stroke patients ${ }^{16}$. However, to our knowledge, there have been few reports on the effect of bilateral lower limb strengthening exercise. There is sufficient evidence that motor function is abnormal on the non-paretic side of individuals

*Corresponding author. Byong Yong Hwang (E-mail: bobathbobath@daum.net)

(C2018 The Society of Physical Therapy Science. Published by IPEC Inc.

(c) (1) $\odot$ This is an open-access article distributed under the terms of the Creative Commons Attribution Non-Commercial No DerivaCC BY NC ND tives (by-nc-nd) License. (CC-BY-NC-ND 4.0: https://creativecommons.org/licenses/by-nc-nd/4.0/) 
following a stroke, as evidenced through muscle weakness ${ }^{17}{ }^{18)}$. Therefore, in this study, both the paretic and non-paretic lower limbs were trained. The purpose of this study was to examine the effects of bilateral lower limb strengthening exercises in hemiparetic stroke patients.

\section{SUBJECTS AND METHODS}

Participants were randomly allocated to either the UTG $(n=10)$ or the BTG $(n=10)$, using a random numbers table. The inclusion criteria were as follows: (1) age $<65$ years; (2) a diagnosis of hemiplegia; (3) $<24$ months after stroke; (4) an ability to understand and follow instructions; and (5) an ability to walk independently for $20 \mathrm{~m}$ without an assistive device. The exclusion criteria were as follows: (1) joint or muscular problems arising from conditions other than stroke; (2) an unstable hypertension or cardiovascular condition, as determined by a physician; and (3) stroke involving the brainstem. Patients in both groups received 60 minutes of therapy, 5 times a week, for a total of 4 weeks. The UTG completed the strengthening exercise only in the paretic lower limb (paretic side, 50 minutes; passive range of motion exercises, 10 minutes). The BTG completed the strengthening exercise in the paretic and non-paretic lower limbs (paretic side, 30 minutes; non-paretic side, 20 minutes; passive range of motion exercises, 10 minutes). The exercise program targeted the hip and the ankle regions. The hip exercise was performed in a prone position with the leg to be exercised positioned off the side of the examination table. With a straight leg, and with a dorsiflexed ankle, the patient slowly raised their leg as high as possible without causing pain, then slowly returned their leg to the starting position and repeated the motion. When performing this exercise, the therapist stabilized the pelvis to prevent the patient from twisting or arching their back. The ankle exercise was performed in a supine position on the examination table. From a relaxed ankle and foot position, the patient dorsiflexed their ankle, keeping the knee straight and holding the position, then slowly returned their foot to the starting position and repeated the motion. The exercises were initiated with moderate assistance and progressed to minimal assistance. The primary outcome measures were the FRT, BBS, TUG, and 10MWT scores. The Wilcoxon signed rank test was used to examine differences arising from treatment. Intergroup differences were analyzed using the Mann-Whitney U test. All statistical analyses were performed using SPSS version 18.0 with a significance level of 0.05 . The data are expressed as mean \pm standard error. This study was approved by the Ethics Committee of Yong In University (Approval Number: 2-1040966-AB-N-01-20-1704-HSR-073-3), and all patients provided written informed consent.

\section{RESULTS}

A total of 20 patients participated in this study. Their clinical characteristics are presented in Table 1. In the BTG, the mean FRT score increased from $13.92 \pm 0.78 \mathrm{~cm}$ to $18.02 \pm 0.70 \mathrm{~cm}(\mathrm{p}<0.05)$. The mean BBS score increased from $40.20 \pm$ 1.31 to $45.10 \pm 1.15(\mathrm{p}<0.05)$. The mean TUG score improved from $29.87 \pm 3.36 \mathrm{sec}$ to $24.31 \pm 2.92 \mathrm{sec}(\mathrm{p}<0.05)$. The mean 10MWT score improved from $25.77 \pm 3.65 \mathrm{sec}$ to $20.85 \pm 3.92 \mathrm{sec}(\mathrm{p}<0.05)$. In the UTG, the mean FRT score increased from $14.03 \pm 0.36 \mathrm{~cm}$ to $15.50 \pm 0.65 \mathrm{~cm}(\mathrm{p}<0.05)$. The mean BBS score increased from $38.50 \pm 0.89$ to $41.30 \pm 1.00(\mathrm{p}<0.05)$. The mean TUG score improved from $27.57 \pm 2.63 \mathrm{sec}$ to $25.98 \pm 2.59 \mathrm{sec}(\mathrm{p}<0.05)$. The mean 10MWT score improved from $25.62 \pm 3.10 \mathrm{sec}$ to $23.63 \pm 3.39 \mathrm{sec}(\mathrm{p}<0.05)$. Both BTG and UTG revealed statistically significant differences in the FRT $(p<0.05)$ and BBS $(p<0.05)$ scores. However, there were no statistically significant differences in the TUG $(p>0.05)$ and 10MWT $(\mathrm{p}>0.05)$ scores (Table 2).

\section{DISCUSSION}

This study showed that 4 weeks of bilateral lower limb strengthening exercise was useful for improving balance in hemiparetic stroke patients. Compared with the UTG, the BTG exhibited greater improvement in FRT and BBS scores. In all the participants, the mean BBS score was $43.20 \pm 0.86$, indicating that all the participants had a high risk of falls ${ }^{19}$ ). In previous studies, BBS scores of $<45$ indicated an increased risk for falls ${ }^{20)}$. Researchers have found that the BBS score on admission to acute inpatient rehabilitation was an important predictor of length of stay ${ }^{21}$. In all the participants, the FRT was $16.85 \pm 0.56 \mathrm{~cm}$. In another study, recurrent falls were associated with an FRT score of $<17.78 \mathrm{~cm}^{22)}$. However, the FRT scores for 13 patients were $<17.78 \mathrm{~cm}$. Previous studies used the FRT to investigate the implications of balance and falls in hemiparetic patients after stroke ${ }^{23)}$. The FRT is a clinical tool to assess the limits of stability and was developed from leaning performance ${ }^{24}$, which involves displacement of the center of pressure at the ankle joint through forward-leaning while maintaining hip extension ${ }^{25}$. As with other forward-oriented movements, a leaning performance generates anticipatory muscle activation in the tibialis anterior muscle prior to displacement of the center of pressure ${ }^{26)}$. This consideration underlines how the FRT score was increased with ankle and hip strengthening exercises. Our study results showed improvements in gait speed in both groups. These results are consistent with findings in previous research ${ }^{27}$. Regarding foot clearance, weakness of the dorsiflexors increased the swing time of the paretic limb ${ }^{28)}$. This may have led to inadequate eccentric contraction in the mid-stance phase, which resulted in decreased loading ability of the paretic limb and increased double-limb support time for slower preparation to the next single-limb support of the paretic limb ${ }^{27)}$. Weakness in the paretic limb dorsiflexors was the result of uncontrolled passive plantarflexor stiffness ${ }^{28}$. Decreased ankle muscle power and plantarflexor moments 
Table 1. Clinical characteristics of the stroke patients

\begin{tabular}{lcc}
\hline Variable & BTG $(\mathrm{n}=10)$ & UTG $(\mathrm{n}=10)$ \\
\hline Age (years) & $42.3 \pm 4.2$ & $43.6 \pm 5.6$ \\
Height $(\mathrm{cm})$ & $165.0 \pm 2.8$ & $166.9 \pm 2.3$ \\
Weight $(\mathrm{kg})$ & $65.5 \pm 4.2$ & $64.0 \pm 1.4$ \\
Gender (M/F) & $6 / 4$ & $7 / 3$ \\
Time since stroke (months) & $15.4 \pm 1.6$ & $15.3 \pm 1.5$ \\
Paretic side (L/R) & $4 / 6$ & $8 / 2$ \\
Type of stroke & $5 / 5$ & $2 / 8$ \\
(ischemic/hemorrhagic) & &
\end{tabular}

BTG: bilateral therapy group; UTG: unilateral therapy group.

Table 2. Changes in outcome measures related to balance and walking after lower limb strengthening exercise

\begin{tabular}{|c|c|c|c|c|c|c|}
\hline \multirow{2}{*}{ Variable } & \multicolumn{3}{|c|}{ BTG } & \multicolumn{3}{|c|}{ UTG } \\
\hline & Pre-test & Post-test & Changes & Pre-test & Post-test & Changes \\
\hline FRT (cm) & $13.92 \pm 0.78$ & $18.20 \pm 0.70 * \dagger$ & $4.28 \pm 0.08$ & $14.03 \pm 0.36$ & $15.50 \pm 0.65^{*} \dagger$ & $1.47 \pm 0.29$ \\
\hline BBS (scores) & $40.20 \pm 1.31$ & $45.10 \pm 1.15^{* \dagger}$ & $4.90 \pm 0.16$ & $38.50 \pm 0.89$ & $41.30 \pm 1.00 * \dagger$ & $2.80 \pm 0.11$ \\
\hline TUG (sec) & $29.87 \pm 3.36$ & $24.31 \pm 2.92^{*}$ & $5.56 \pm 0.44$ & $27.57 \pm 2.63$ & $25.98 \pm 2.59^{*}$ & $1.59 \pm 0.04$ \\
\hline 10MWT (sec) & $25.77 \pm 3.65$ & $20.85 \pm 3.92 *$ & $4.92 \pm 0.27$ & $25.62 \pm 3.10$ & $23.63 \pm 3.39 *$ & $1.99 \pm 0.29$ \\
\hline
\end{tabular}

BTG: bilateral therapy group; UTG: unilateral therapy group; FRT: functional reach test; BBS: Berg balance scale; TUG: timed up and go; 10MWT: 10-meter walk test.

${ }^{*} \mathrm{p}<0.05=$ significant difference between pre-test and post-test.

$\dagger \mathrm{p}<0.05=$ significant difference between BTG and UTG.

in non-paretic limbs have previously been studied during gait in stroke patients ${ }^{29)}$. Our results indicate that lower limb strengthening exercises should also be emphasized for stroke patients to achieve faster walking speed. Deficits in lower limb muscle strength are a critical aspect of functional disability and are frequently assessed in rehabilitation ${ }^{30)}$. There is a significant relationship between non-paretic lower limb muscle strength and functions such as stair climbing and walking $^{31)}$. Researchers have shown that substantial weakness is present in the paretic and non-paretic limbs of stroke patients ${ }^{32}$. Indeed, there are several mechanisms that impair voluntary muscle activation, and disuse atrophy and alterations in skeletal muscle composition and structure have been implicated in this muscle strength deficit after stroke ${ }^{33}$. One report on weakness in the non-paretic limb has suggested that consideration should also be given to the muscle strength of both limbs ${ }^{17)}$. It is possible that these neurophysiological and structural alterations, suggested as mechanisms for muscle weakness, may cause secondary problems, due to disruption of the corticospinal tract (CST). Consequently, the extent of CST damage may affect muscle weakness after stroke ${ }^{34)}$. The extent of CST damage has been demonstrated to predict the degree of clinical amelioration after stroke ${ }^{35)}$. In addition, evidence indicates that the physiological integrity of the CST positively affects motor performance in the lower limb in stroke patients ${ }^{36}$. It is well documented that some CST do not cross at the pyramidal decussation. The estimated percentage of uncrossed tracts is approximately $10-20 \%$. These uncrossed ipsilateral tracts have been implicated as a possible after-stroke recovery mechanism ${ }^{37)}$, and researchers have proposed that they could be activated with bilateral training ${ }^{38)}$. Anatomically, the "unmasking" of uncrossed ipsilateral CST from the non-paretic hemisphere ${ }^{39)}$ may be accountable for offsetting of the normal inhibition of the spinal circuits with bilateral homologous activation ${ }^{40)}$. Alterations of descending circuitry and somatosensory feedback from the non-paretic limb can modulate muscle activation in the paretic limb. Moreover, tracts connecting the lower limbs appear to be enhanced after stroke ${ }^{41)}$. Kautz et al. ${ }^{41)}$ proposed that, after stroke, individuals may experience a loss of inhibition of the excitatory interlimb pathways that become activated for bilateral activation. The results of this study have meaningful implications for physical therapists and researchers who focus on improving rehabilitation after stroke. However, considering the small number of patients, caution must be applied since this finding might not be generalizable to all hemiparetic patients after stroke. Further studies should examine whether strengthening exercises in the bilateral lower limbs of hemiparetic patients after stroke are beneficial for balance. Although rehabilitation is usually focused on the paretic side, it appears that more attention needs to be given to the non-paretic side to improve balance.

\section{Conflict of interest}

None. 


\section{REFERENCES}

1) Eng JJ: Strength training in individuals with Stroke. Physiother Can, 2004, 56: 189-201. [Medline] [CrossRef]

2) Gresham GE, Fitzpatrick TE, Wolf PA, et al.: Residual disability in survivors of stroke— the Framingham study. N Eng1 J Med, 1975, 293: 954-956. [Medline] [CrossRef]

3) Arene N, Hidler J: Understanding motor impairment in the paretic lower limb after a stroke: a review of the literature. Top Stroke Rehabil, 2009 , 16: 346-356. [Medline] [CrossRef]

4) Bohannon RW, Walsh S: Nature, reliability, and predictive value of muscle performance measures in patients with hemiparesis following stroke. Arch Phys Med Rehabil, 1992, 73: 721-725. [Medline]

5) Bohannon RW: Selected determinants of ambulatory capacity in patients with hemiplegia. Clin Rehabil, 1989, 3: 47-53. [CrossRef]

6) Bohannon RW: Determinants of transfer capacity in patients with hemiplegia. Physiother Can, 1988, 40: 236-239.

7) Bohannon RW, Walsh S: Association of paretic lower extremity muscle strength and standing balance with stair-climbing ability in patients with stroke. J Stroke Cerebrovasc Dis, 1991, 1: 129-133. [Medline] [CrossRef]

8) Wade DT, Hewer RL: Motor loss and swallowing difficulty after stroke: frequency, recovery, and prognosis. Acta Neurol Scand, 1987, 76: 50-54. [Medline] [CrossRef]

9) Bourbonnais D, Vanden Noven S: Weakness in patients with hemiparesis. Am J Occup Ther, 1989, 43: 313-319. [Medline] [CrossRef]

10) Andrews AW, Bohannon RW: Discharge function and length of stay for patients with stroke are predicted by lower extremity muscle force on admission to rehabilitation. Neurorehabil Neural Repair, 2001, 15: 93-97. [Medline] [CrossRef]

11) Wade DT, Langton-Hewer R, Wood VA, et al.: The hemiplegic arm after stroke: measurement and recovery. J Neurol Neurosurg Psychiatry, 1983 , 46 : 521-524. [Medline] [CrossRef]

12) Sunderland A, Tinson D, Bradley L, et al.: Arm function after stroke. An evaluation of grip strength as a measure of recovery and a prognostic indicator. J Neurol Neurosurg Psychiatry, 1989, 52: 1267-1272. [Medline] [CrossRef]

13) Eng JJ, Kim CM, Macintyre DL: Reliability of lower extremity strength measures in persons with chronic stroke. Arch Phys Med Rehabil, 2002 , 83: 322-328. [Medline] [CrossRef]

14) Engardt M, Knutsson E, Jonsson M, et al.: Dynamic muscle strength training in stroke patients: effects on knee extension torque, electromyographic activity, and motor function. Arch Phys Med Rehabil, 1995, 76: 419-425. [Medline] [CrossRef]

15) Teixeira-Salmela LF, Olney SJ, Nadeau S, et al.: Muscle strengthening and physical conditioning to reduce impairment and disability in chronic stroke survivors. Arch Phys Med Rehabil, 1999, 80: 1211-1218. [Medline] [CrossRef]

16) Whitall J, McCombe Waller S, Silver KH, et al.: Repetitive bilateral arm training with rhythmic auditory cueing improves motor function in chronic hemiparetic stroke. Stroke, 2000, 31: 2390-2395. [Medline] [CrossRef]

17) Bohannon RW, Andrews AW: Limb muscle strength is impaired bilaterally after stroke. J Phys Ther Sci, 1995, 7: 1-7. [CrossRef]

18) Sjöström M, Fugl-Meyer AR, Nordin G, et al.: Post-stroke hemiplegia; crural muscle strength and structure. Scand J Rehabil Med Suppl, 1980 , 7: 53-67. [Medline]

19) Shumway-Cook A, Baldwin M, Polissar NL, et al.: Predicting the probability for falls in community-dwelling older adults. Phys Ther, 1997, 77 : $812-819$. [Medline] [CrossRef]

20) Berg KO, Wood-Dauphinee SL, Williams JI, et al.: Measuring balance in the elderly: validation of an instrument. Can J Public Health, 1992, 83: S7-S11. [Medline]

21) Wee JY, Bagg SD, Palepu A: The Berg balance scale as a predictor of length of stay and discharge destination in an acute stroke rehabilitation setting. Arch Phys Med Rehabil, 1999, 80: 448-452. [Medline] [CrossRef]

22) Duncan PW, Studenski S, Chandler J, et al.: Functional reach: predictive validity in a sample of elderly male veterans. J Gerontol, 1992, 47: M93-M98. [Medline] [CrossRef]

23) Katz-Leurer M, Fisher I, Neeb M, et al.: Reliability and validity of the modified functional reach test at the sub-acute stage post-stroke. Disabil Rehabil, 2009, 31: 243-248. [Medline] [CrossRef]

24) Duncan PW, Weiner DK, Chandler J, et al.: Functional reach: a new clinical measure of balance. J Gerontol, 1990, 45: M192-M197. [Medline] [CrossRef]

25) King MB, Judge JO, Wolfson L: Functional base of support decreases with age. J Gerontol, 1994, 49: M258-M263. [Medline] [CrossRef]

26) Crenna P, Frigo C: A motor programme for the initiation of forward-oriented movements in humans. J Physiol, 1991, 437: 635-653. [Medline] [CrossRef]

27) Lin PY, Yang YR, Cheng SJ, et al.: The relation between ankle impairments and gait velocity and symmetry in people with stroke. Arch Phys Med Rehabil, 2006, 87: 562-568. [Medline] [CrossRef]

28) Lamontagne A, Malouin F, Richards CL, et al.: Mechanisms of disturbed motor control in ankle weakness during gait after stroke. Gait Posture, 2002, 15: 244-255. [Medline] [CrossRef]

29) Olney SJ, Richards C: Hemiparetic gait following stroke. Part I: characteristics. Gait Posture, 1996, 4: 136-148. [CrossRef]

30) Adams RW, Gandevia SC, Skuse NF: The distribution of muscle weakness in upper motoneuron lesions affecting the lower limb. Brain, 1990, 113: 1459-1476. [Medline] [CrossRef]

31) Kim CM, Eng JJ: The relationship of lower-extremity muscle torque to locomotor performance in people with stroke. Phys Ther, 2003, 83: 49-57. [Medline]

32) Gerrits KH, Beltman MJ, Koppe PA, et al.: Isometric muscle function of knee extensors and the relation with functional performance in patients with stroke. Arch Phys Med Rehabil, 2009, 90: 480-487. [Medline] [CrossRef]

33) Horstman AM, Beltman MJ, Gerrits KH, et al.: Intrinsic muscle strength and voluntary activation of both lower limbs and functional performance after stroke. Clin Physiol Funct Imaging, 2008, 28: 251-261. [Medline] [CrossRef]

34) Madhavan S, Krishnan C, Jayaraman A, et al.: Corticospinal tract integrity correlates with knee extensor weakness in chronic stroke survivors. Clin Neurophysiol, 2011, 122: 1588-1594. [Medline] [CrossRef]

35) Stinear CM, Barber PA, Smale PR, et al.: Functional potential in chronic stroke patients depends on corticospinal tract integrity. Brain, 2007, 130: 170-180. 
[Medline] [CrossRef]

36) Madhavan S, Rogers LM, Stinear JW: A paradox: after stroke, the non-lesioned lower limb motor cortex may be maladaptive. Eur J Neurosci, 2010, 32: 1032-1039. [Medline] [CrossRef]

37) Chollet F, DiPiero V, Wise RJ, et al.: The functional anatomy of motor recovery after stroke in humans: a study with positron emission tomography. Ann Neurol, 1991, 29: 63-71. [Medline] [CrossRef]

38) Mudie MH, Matyas TA: Can simultaneous bilateral movement involve the undamaged hemisphere in reconstruction of neural networks damaged by stroke? Disabil Rehabil, 2000, 22: 23-37. [Medline] [CrossRef]

39) Kim YH, Jang SH, Byun WM, et al.: Ipsilateral motor pathway confirmed by combined brain mapping of a patient with hemiparetic stroke: a case report. Arch Phys Med Rehabil, 2004, 85: 1351-1353. [Medline] [CrossRef]

40) Khodiguian N, Cornwell A, Lares E, et al.: Expression of the bilateral deficit during reflexively evoked contractions. J Appl Physiol 1985, 2003, 94: 171-178. [Medline] [CrossRef]

41) Kautz SA, Patten C, Neptune RR: Does unilateral pedaling activate a rhythmic locomotor pattern in the nonpedaling leg in post-stroke hemiparesis? J Neurophysiol, 2006, 95: 3154-3163. [Medline] [CrossRef] 